\title{
LA CORTE CONSTITUCIONAL Y SUS PRONUNCIAMIENTOS SOBRE LAS POBLACIONES QUE CARECEN DEL CONSUMO DE AGUA POTABLE
}

\author{
Autores Ruth Esther Estarita Giraldo \\ Correspondencia en: angiestarita@hotmail.com.
}

\begin{abstract}
RESUMEN
El propósito de este artículo constituye el pronunciamiento que ha establecido la Corte Constitucional sobre el derecho fundamental al consumo del agua potable en aquellas poblaciones donde no hay este preciado líquido, necesario para satisfacer todas las formas de vivir. En Colombia la Corte Constitucional a través de las sentencias T-578/2010 y T-082/2013 manifiesta que el agua potable tiene el carácter fundamental, ya que hace referencia a su poder vinculante frente a todos los poderes públicos, es por ello que mediante tutela se logra hacer vales este derecho.
\end{abstract}

\section{Palabras Claves}

Agua potable, Salubridad, Vida, Servicios públicos domiciliarios, Estado, Acción de tutela, Acción popular,

\begin{abstract}
The intention of this article constitutes the pronouncement that has established the Constitutional Court on the fundamental right to the consumption of the drinkable water in those populations where there is no valued liquid, necessary this one to satisfy all the ways of living. In Colombia the Constitutional Court across the judgments T-578/2010 and T-082/2013 demonstrates that the drinkable water has the fundamental character, since it refers to his binding power opposite to all the public power, is for it that by means of guardianship is achieved to do you cost this right.
\end{abstract}

\section{Keywords}

Drinkable water, Health, Life, Public domiciliary services, Estado, Action of guardianship, Popular action.

\footnotetext{
${ }^{1}$ Abogada litigante.
} 


\section{INTRODUCCIÓN}

El estudio está relacionado con el consumo del agua potable, ya que este líquido preciado es necesario para satisfacer todas las formas de vivir. En por ello que en Colombia La Corte Constitucional se ha manifestado sobre el derecho al agua, entendiendo que este tiene el carácter fundamental. El agua potable como derecho tiene un alcance subjetivo y objetivo; es objetivo por cuanto como derecho fundamental porque hace referencia a su poder vinculante frente a todos los poderes públicos, por consiguiente por estar en conexidad o amparado por los derechos fundamentales, constituye un sistema de valores positivistas de la Constitución que guía las decisiones de todas las autoridades, y derecho subjetivo porque al acudir a la tutela del agua, esta puede ser reclamada ante las instancias judiciales en escenarios de vulneración por el Estado o también por particulares, especialmente cuando se trata del consumo humano.

La importancia de lo antes mencionado ha dado lugar al nacimiento de esta línea jurisprudencial para determinar la protección por medio de la acción de tutela al consumo del agua. En la Constitución Política colombiana (2001) no se consagra expresamente el derecho al agua como un derecho fundamental. Sin embargo, en virtud del contenido del Artículo 93 Superior que preceptúa: "Los tratados y convenios internacionales ratificados por el Congreso, que reconocen los derechos humanos y que prohíben su limitación en los estados de excepción, prevalecen en el orden interno" (Sentencia C-067/03); esta garantía hace parte del catálogo de derechos fundamentales que cualquier ciudadano puede invocar para solicitar su protección bajo nuestro ordenamiento constitucional, teniendo en cuenta que es reconocida en varios instrumentos internacionales de derechos humanos, como más adelante se analizará. 
En otras palabras, en virtud de la figura jurídica del bloque de constitucionalidad el derecho al agua ha sido incorporado al ordenamiento jurídico interno para enriquecer el capítulo de derechos fundamentales de la Carta Superior. Ahora bien, uno de los instrumentos internacionales a partir de los cuales se ha reconocido el derecho al agua es el Pacto Internacional de Derechos Económicos, Sociales y Culturales (PIDESC),

\section{MATERIALES Y MÉTODOS}

La metodología de esta investigación es deductiva porque se realizó con la ayuda de las diferentes Sentencias, entre las cuales se citan: La Sentencia T- 578 de 1992, Expediente T- 1848; La Sentencia T- 418 de 2010, Expediente T-252812 y la Sentencia T- 082 de 19 de 2013. Además, se requirió de lecturas, para llegar a casos particulares en los cuales se obtuvo la solución para aplicar su normatividad.

\section{RESULTADOS Y DISCUSIÓN}

La tutela ampara y protege los derechos fundamentales, y para este caso es de vital importancia el consumo del agua potable y este debe ser suficiente, salubre, aceptable, accesible y asequible para su uso personal y domestico, por estas razones se debe amparar aun mas a aquellas poblaciones que carecen de cualquier barrera física o económica que impida el uso y servicio del acceso al agua potable.

Los resultados obtenidos en este análisis son deductivos ya que se realizó una exhaustiva lectura para llegar a la conclusión que La Corte Constitucional a pesar que no ha fallado a favor las tutelas instauradas por los accionantes fundamentándose en la existencia de otros medios judiciales, que permitan lograr la protección del derecho invocado, ha aclarado en reiteradas ocasiones lo 


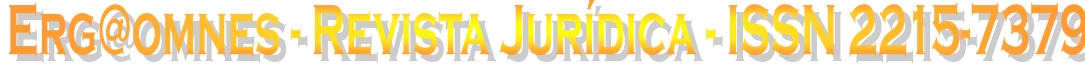

Vol. 6, No. 1 Diciembre de 2014 pp. 49 - 55

importante que es la protección de este derecho tan vital e importante para todos y cada uno de los ciudadanos.

Desde un principio el Estado tiene la obligación constitucional de prestar eficientemente los servicios públicos domiciliarios, ya sea de forma directa o indirecta a través de entidades territoriales o particulares. Sin embargo, en cualquier caso el Estado mantiene la facultad de regulación, control y vigilancia de dichos servicios, lo anterior con la finalidad de que sean prestados de manera eficiente a todos los ciudadanos.

Se encuentra en esta investigación que tiene como punto arquimédico la Sentencia T- 082 de 19 de febrero de 2013 Expediente T-3.603.506 (Colombia. Corte Constitucional, 2013), por ser la que se tomó como referencia al momento de iniciar esta línea jurisprudencial; la Sentencia hito es la T- 418 de 25 de mayo de 2010, Expediente t-252812 (Colombia. Corte Constitucional, 2010) por ser mencionada varias veces en el punto arquimédico. En esta línea jurisprudencial existe una ruptura ya que la Sentencia T- 578/1992 (Colombia. Corte Constitucional, 1992) es la que reconoce el agua como un derecho fundamental que a pesar de negar la tutela por existir otros medios de defensa judicial. La sala de tutela consideró este derecho como fundamental por ser fuente de vida, indicando lo siguiente:

El agua constituye fuente de vida y la falta del servicio atenta directamente contra el derecho fundamental a la vida de las personas. Así pues, el servicio público domiciliario de acueducto y alcantarillado en tanto que afecte la vida de las personas, la salubridad pública o la salud, es un derecho constitucional fundamental y como tal debe ser objeto de protección a través de la acción de tutela. La discusión que se plantea es que con esta providencia a partir de ella la corte toma en cuenta a la hora de fallar este derecho fundamental siempre y cuando obtenga los requisitos establecidos para garantizar el consumo del agua 
Vol. 6, No. 1 Diciembre de 2014 pp. 49 - 55

potable en aquellas poblaciones en donde es difícil su instalación y servicio las cuales han sido vulneradas por las autoridades competentes.

En términos generales y como un recuento histórico alrededor de las Sentencias que han sido promulgadas por la Corte Constitucional en cuanto al servicio de agua potable, se tiene lo siguiente: ¿cómo se ha pronunciado la Corte Constitucional sobre las poblaciones que carecen del consumo de agua potable?

\begin{tabular}{|c|c|}
\hline SI & NO \\
\cline { 1 - 1 } Sentencia T 418 2010 & Sentencia T-578 1992 \\
\cline { 1 - 1 } Sentencia T 082 2013 & \\
\hline
\end{tabular}

\section{CONCLUSIÓN}

El derecho al consumo del agua potable nace desde la necesidad de aquellas personas que encontramos en las sentencias, no olvidando que en ciudades también ocurre la vulneración de este derecho, es por ello que la corte constitucional manifiesta que el agua es un derecho fundamental porque su servicio debe ser digno para que pueda ser garantizado, esta investigación concluyo que el agua que estaban consumiendo los habitantes del la vereda del municipio de Arbeláez que a pesar de no contar con la instalación del servicio de agua ya que son pequeñas y no cuentan con los parámetros requeridos para tener una planta de tratamiento con la cual se facilite la potabilización del agua para consumo humano, aun así estas familias o afectados buscaban con sus propios medios obtener el preciado liquido, que bajo una investigación el agua que llegaba a sus viviendas contenía residuos fecales que producía daños estomacales comúnmente llamados "diarreicos”. 
Sin embargo la Corte manifiesta que para que este servicio de agua potable deba darse, siempre y cuando exista la necesidad, que exista la prueba que son titulares de la viviendas donde habitan, y solo se podrá negar las solicitudes de servicios por razones de carácter Técnico y/o por no encontrarse dentro del programa de inversiones de la Empresa, es de saberse que la administración violó los derechos de estas familias. La investigación procede a concluir que la acción de tutela es procedente como mecanismo transitorio ya que existe una amenaza que recae sobre un derecho fundamental, y no otro medio de defensa judicial, ya que con el fallo obtenido de manera inmediata se podrá resarcir a tiempo los daños si es posible, por lo tanto el agua constituye fuente de vida y la falta del servicio atenta directamente con el derecho fundamental a la vida de las personas. Así pues el servicio público domiciliario de acueducto y alcantarillado en tanto que afecte la vida de las personas, la salubridad pública o la salud, es un derecho constitucional fundamental y como tal ser objeto de protección a través de la acción de tutela (Sentencia T-740/).

El estado social de derecho exige esforzarse en la construcción de condiciones dignas para vivir, por ello la prioridad del agua potable como derecho fundamental enriquece las condiciones necesarias de cualquier persona para vivir en dignidad, la corte constitucional cuando ampara el derecho al agua potable busca mejorar las desigualdades que existen en este servicio porque a su sabio entender esa regulación, control y vigilancia que los servicios públicos domiciliarios sean brindados de manera eficiente a los ciudadanos le corresponde al Estado.

\section{BIBLIOGRAFÍA}


Bernal C. (2006). Metodología de la investigación. México: Pearson Educación

Colombia. Asamblea Nacional Constituyente. (2001). Constitución Política de Colombia, 2001. Bogotá,

Colombia. Corte Constitucional. (1992). Sentencia T- 578 de 3 Noviembre de 1992. .

Colombia. Corte Constitucional (2010). Sentencia T- 418 de 25 de mayo de 2010.

Colombia. Corte Constitucional. (2013). Sentencia T- 082 de 19 de febrero de 2013.

http://revista.urepublicana.edu.co/wpcontent/uploads/2012/07/El-Derecho-al-aguapotable-en-la-jurisprudencia-colombiana.pdf.

López. D. (2006). El derecho de los jueces. Bogotá: legis 